\title{
Normal growth and intravascular volume status with good metabolic control during peritoneal dialysis in infancy
}

\author{
Hanne Laakkonen • Juha-Matti Happonen • \\ Eino Marttinen • Aila Paganus • Tuula Hölttä • \\ Christer Holmberg • Kai Rönnholm
}

Received: 6 August 2009/Revised: 5 April 2010 /Accepted: 7 April 2010 /Published online: 6 May 2010

(C) The Author(s) 2010. This article is published with open access at Springerlink.com

\begin{abstract}
The most demanding patient population on peritoneal dialysis (PD) consists of children under 2 years of age. Their growth is inferior to that of older children and maintaining euvolemia is difficult, especially in anuric patients. In this prospective study reported here, we enrolled 21 patients $<2$ years of age (mean 0.59 years) at onset of PD and monitored their uremia parameters and evaluated their nutrition. Since no good instrument currently exists for estimating intravascular volume status, we used traditional blood pressure measurements, echocardiography, and N-terminal atrial natriuretic peptide measurements. Growth was compared with midparental height. Metabolic control was good. Long-term hypertension was seen in $43 \%$ of the patients, but left ventricular hypertrophy decreased during the study period. Mean weekly urea Kt/V was $3.38 \pm$
\end{abstract}

H. Laakkonen · A. Paganus · T. Hölttä • C. Holmberg •

K. Rönnholm

Department of Pediatric Nephrology and Transplantation, Hospital for Children and Adolescents,

Helsinki University Central Hospital, University of Helsinki,

Helsinki, Finland

J.-M. Happonen

Department of Pediatric Cardiology,

Hospital for Children and Adolescents,

Helsinki University Central Hospital, University of Helsinki,

Helsinki, Finland

\section{E. Marttinen}

Department of Pediatric Radiology,

Hospital for Children and Adolescents,

Helsinki University Central Hospital, University of Helsinki,

Helsinki, Finland

H. Laakkonen $(\bowtie)$

Biomedicum 2C Helsinki,

Tukholmankatu 8 C, 6.krs, PL 705, 00029 HUS Helsinki, Finland

e-mail: hanne.laakkonen@hus.fi
0.66 and creatinine clearance was $49 \pm 20 \mathrm{~L} /$ week per $1.73 \mathrm{~m}^{2}$. Catch-up growth was documented in $57 \%$ of the patients during PD. However, these children did not attain their midparental height at the end of PD at a mean age of 1.71 years. Although favorable metabolic control and good growth were achieved during PD, these children lagged in term of their midparental height. We conclude that several instruments are needed for determining the management of intravascular volume status and that the control of calciumphosphorus status is demanding.

Keywords Adequacy · Blood pressure - Growth · Infants . Intravascular volume status $\cdot$ Metabolic control .

Peritoneal dialysis $\cdot$ Small children

\section{Introduction}

Doubts were expressed for many years on whether infants and small children should be treated with peritoneal dialysis (PD), and not all centers offered this treatment possibility [1-4]. Currently, PD is widely used and technically feasible due to good surgical techniques, small catheters and tubings, and the development of special dialysis machines and programs for patients in this age group. However, hypervolemia-associated problems, such as hypertension and cardiac hypertrophy, are still major concerns [5]. In addition, although growth is "normal for age" $[6,7]$, it may not correspond to the target height of the child.

The dialysis period has been found to be the most critical time in terms of the potential for the development of complications, leading to life-long disabilities in small children with end-stage renal failure. For example, hemodynamic crises may lead to serious sequelae [8]. Clinical status and blood pressure measurements do not provide 
sufficient information for a precise estimation of the intravascular volume status. However, in a study on Finnish patients, Hölttä et al. showed that pulmonary edema- and hypervolemia-associated seizures could be avoided in small children on PD [6, 9], although hypertension and the need for antihypertensive medication were still common in infants, especially if nephrectomized [6]. On the other hand, hypovolemia and severe hypotension may cause brain damage and visual disability [7, 10]. Left ventricular hypertrophy (LVH) is considered to be an important marker of cardiovascular disease [11] and has been detected in $60 \%$ of PD patients under 5 years of age [5]. Yet defining left ventricular mass (LVM) and LVH is not clear and absolute [11], and small children constitute a special challenge [12]. These issues should be further evaluated.

In a prior retrospective analysis of the growth of infants on PD, we noted that the infants on PD had an average weekly urea $\mathrm{Kt} / \mathrm{V}>3$ and a creatinine clearance $\left(\mathrm{C}_{\mathrm{cr}}\right)$ of $>70 \mathrm{~L} /$ week per $1.73 \mathrm{~m}^{2}$ [6]. These are clearly higher than the adult targets for $\mathrm{PD}$, which are a weekly urea $\mathrm{Kt} / \mathrm{V} \geq 2.1$ and $\mathrm{C}_{\mathrm{cr}} \geq 63 \mathrm{~L} /$ week per $1.73 \mathrm{~m}^{2}$ [13]. However, these results overestimate the clearances by up to $15 \%$ due to the dialysate and urine collection method [6].

To further maximize growth and development in this age group, we initiated a study emphasizing these problems. Here, we report on the nutrition, metabolic control, solute clearances, intravascular volume status, heart measures, and growth compared with midparental height in 21 prospectively followed infants treated by the same PD protocol since 2001 . Neurological and psychosocial development of these infants will be presented in detail in a subsequent report.

\section{Materials and methods}

\section{Patients}

All children $<2$ years of age at onset of PD who were treated at our institution between 2001 and 2005 were enrolled in this prospective study $(n=21)$. The clinical characteristics of the patients are presented in Table 1 . Bilateral nephrectomy was performed in 17 infants (81\%).

\section{Follow-up}

The initiation of all chronic PD treatments as well as family training were performed in the Hospital for Children and Adolescents in Helsinki. Registered nurses began home visits during the family training period to support the family in implementing PD in the home situation. The children visited our pediatric nephrology ward 1 and 3 months after the initiation of PD and every third month thereafter. Laboratory tests, growth measurements, 24-h dialysate, and urine collection for clearances, intraperitoneal pressure (IPP) measurements, blood pressure, and heart ultrasound were performed during the visits. The families also met regularly with our dietician. Follow-up at local hospitals occurred every 1-3 weeks. This study terminated at renal transplantation or if the patient was permanently transferred to hemodialysis (HD).

\section{Dialysis}

The same two urologists inserted all dialysis catheters 2 weeks before nephrectomy and dialysis initiation. In two children dialysis had to be initiated a few days after catheter insertion. We used the Tenkhoff curled 1-cuff catheter. The exit site was in the lateral position with the head of the catheter oriented upwards. The fill volume was $800 \mathrm{~mL} / \mathrm{m}^{2}$ of body surface area (BSA) in children $<1$ year of age and $1000 \mathrm{~mL} / \mathrm{m}^{2}$ of BSA in older children.

The IPP was measured with a technique described by Durand et al. [14] and applied to children by Fischbach et al. $[15,16]$. It was targeted to remain under $10 \mathrm{~cm}$ of water in children $<2$ years of age and $<16 \mathrm{~cm}$ of water in older patients. The upper limit of IPP was lower in younger children because high pressure exposes the patient to discomfort, vomiting, and hernias, which already were frequent problems in these patients.

Continuous cycling peritoneal dialysis (CCPD) was the first choice of modality. Nightly dialysis treatment time was 10-11 h, including 12-14 exchanges and the last fill of $50 \%$ of the nightly dwell volume. Children with outflow pain or ultrafiltration problems were switched to tidal peritoneal dialysis (TPD). TPD was also used in some infants to obtain better clearance. The treatment time on TPD was also $10-11 \mathrm{~h}$ per night, and 22-26 exchanges were performed with $50 \%$ fluid exchange per cycle. One full outflow was performed in the middle of the program for safety reasons, i.e. to avoid excess of fill. In nephrectomized patients, two daytime dialysate exchanges, with a volume of about $50 \%$ of the nightly dwell volume, were performed in the afternoon to avoid hypervolemia. All patients used the Baxter Home Choice cycler PD machine (Baxter Healthcare Corp, Deerfield, IL). The dialysis solution was pH-neutral bicarbonate-lactate-buffered dextrose solution (Physioneal; Baxter Healthcare Corp). All dextrose concentrations were used, and weight limits were used to determine the glucose concentration needed for night and daytime exchanges [9]. Nightly PD was usually performed with a mixture of low- and medium-glucose concentration fluids, while mostly medium- and highglucose concentrations were used in daytime exchanges to obtain better ultrafiltration with smaller fill volumes.

After every 24-h dialysate (and urine) collection, the patient's dialysis program was individually planned and 
Table 1 Clinical characteristics of the patient cohort $^{\mathrm{a}}(n=21)$

\begin{tabular}{|c|c|c|c|c|c|c|c|c|c|}
\hline $\begin{array}{l}\text { Patient } \\
\text { no. }\end{array}$ & Sex & Diagnosis & $\begin{array}{l}\text { Nephrectomy } \\
\text { (none/bilateral) }\end{array}$ & $\begin{array}{l}\text { PD start } \\
\text { age (years) }\end{array}$ & $\begin{array}{l}\text { PD duration } \\
\text { (years) }\end{array}$ & $\begin{array}{l}\text { Peritonitis } \\
\text { number }\end{array}$ & $\begin{array}{l}\text { Exit site and } \\
\text { tunnel } \\
\text { information }\end{array}$ & $\begin{array}{l}\text { Catheter } \\
\text { complications }\end{array}$ & PD ended in \\
\hline 1 & M & $\mathrm{CNF}$ & Bilateral & 0.4 & 0.7 & - & - & No & $\mathrm{Tx}$ \\
\hline 2 & F & $\mathrm{CNF}$ & Bilateral & 0.4 & 1.9 & 3 & 1 & Yes & Tx \\
\hline 3 & M & $\mathrm{CNF}$ & Bilateral & 0.5 & 0.6 & - & - & Yes & Tx \\
\hline 4 & M & $\mathrm{CNF}$ & Bilateral & 0.5 & 0.6 & - & - & Yes & Tx \\
\hline 5 & M & $\mathrm{CNF}$ & Bilateral & 0.5 & 1.1 & - & 1 & No & $\mathrm{Tx}$ \\
\hline 6 & M & $\mathrm{CNF}$ & Bilateral & 0.5 & 0.5 & - & 1 & Yes & Exitus \\
\hline 7 & M & $\mathrm{CNF}$ & Bilateral & 0.6 & 1.2 & - & 1 & Yes & $\mathrm{Tx}$ \\
\hline 8 & $\mathrm{~F}$ & $\mathrm{CNF}$ & Bilateral & 0.6 & 1.5 & - & 2 & Yes & $\mathrm{Tx}$ \\
\hline 9 & M & $\mathrm{CNF}$ & Bilateral & 0.7 & 0.6 & - & 1 & No & $\mathrm{Tx}$ \\
\hline 10 & $\mathrm{~F}$ & $\mathrm{CNF}$ & Bilateral & 0.7 & 1.0 & - & 1 & No & $\mathrm{Tx}$ \\
\hline 11 & $\mathrm{~F}$ & $\mathrm{CNF}$ & Bilateral & 0.7 & 1.1 & 3 & - & No & $\mathrm{Tx}$ \\
\hline 12 & M & $\mathrm{CNF}$ & Bilateral & 0.8 & 0.9 & - & - & No & $\mathrm{Tx}$ \\
\hline 13 & M & $\mathrm{CNF}$ & Bilateral & 0.8 & 1.6 & - & 1 & No & $\mathrm{Tx}$ \\
\hline 14 & $\mathrm{~F}$ & $\mathrm{CNF}$ & Bilateral & 1.0 & 0.9 & 3 & - & Yes & HD \\
\hline 15 & M & $\mathrm{CNF}$ & Bilateral & 1.1 & 0.9 & 1 & 1 & No & $\mathrm{Tx}$ \\
\hline 16 & $\mathrm{~F}$ & ARPKD & Bilateral & 0.0 & 0.5 & 1 & 1 & Yes & HD \\
\hline 17 & $\mathrm{~F}$ & Midaortic disease & Bilateral & 1.3 & 2.3 & 3 & 1 & No & HD \\
\hline 18 & $\mathrm{~F}$ & $\begin{array}{l}\text { Multicystic kidney } \\
\text { dysplasia }\end{array}$ & None & 0.0 & 2.5 & 1 & 1 & Yes & $\mathrm{Tx}$ \\
\hline 19 & M & Urethral valve & None & 0.0 & 1.0 & 1 & - & No & $\mathrm{Tx}$ \\
\hline 20 & M & Hypoxemic renal injury & None & 0.4 & 1.5 & - & - & No & $\mathrm{Tx}$ \\
\hline 21 & $\mathrm{~F}$ & $\begin{array}{l}\text { Townes-Brocks } \\
\text { syndrome }\end{array}$ & None & 0.7 & 0.9 & - & - & No & $\mathrm{Tx}$ \\
\hline
\end{tabular}

M, Male; F, female; CNF, congenital nephrotic syndrome of the Finnish type; ARPKD, autosomal recessive polycystic kidney disease; PD peritoneal dialysis; Tx, renal transplantation; $\mathrm{HD}$, transferred permanently to hemodialysis

${ }^{\mathrm{a}}$ All patients were $<2$ years of age at initiation of PD. Mean age at initiation of PD was 0.59 years, mean duration of PD was 1.13 years, and peritonitis rate was one episode per 17.8 patient-months

altered according to the general condition and metabolic balance as determined using the PD Adequest 2.0 computer program (Baxter Healthcare). The dialysis program could be carried out during daily routine using clearance values for weekly urea $\mathrm{Kt} / \mathrm{V}$ and $\mathrm{C}_{\mathrm{cr}}$ that were nearest to our goals (see laboratory values and solute clearance). This program was originally planned for 3 months; however, the dialysate volume was increased between visits to the clinic as the patient grew and if metabolic control values, such as blood, urea, nitrogen, and plasma phosphate, were deteriorating and the preceding IPP was lower than our upper limit.

\section{Nutrition}

Nutrition was planned at initiation of PD and evaluated monthly or, if needed, even weekly by the same dietician. The energy provided was $80-90 \mathrm{kcal} / \mathrm{kg}$ per day, and the amount of protein provided was $2.0-2.5 \mathrm{~g} / \mathrm{kg}$ per day [17], depending on the growth velocity of the patient. Sixteen patients needed permanent nasogastric tubes, and one patient needed a gastrostomy to ensure adequate energy intake. Food intake was calculated from 2-day food records $(n=42,14$ patients), and the energy, protein, and nutrient measures in the diet were counted with the Aivo2000 Diet32 program, ver. 1.4.4.1 (Aivo Finland Oy, Turku, Finland). The diet consisted of infant milk and cereal products with energy supplements [6]. Additional energy from dialysis solutions (glucose) was estimated to be approximately $10 \mathrm{kcal} / \mathrm{kg}$ per day and was not included in the nutrition analyses. Metabolic control was considered to be favorable, with normal growth for age and internationally accepted plasma creatinine and blood urea nitrogen concentrations, with hemoglobin and $\mathrm{pH}$ normal for age.

\section{Medication}

All patients received regular medication for their end-stage renal failure. Subcutaneous erythropoietin and oral iron supplementation were given to achieve a hemoglobin concentration of at least the minimum age-related reference 
values $(100-120 \mathrm{~g} / \mathrm{L})$. Calcium carbonate was given as a calcium supplement and a phosphate binder, and alphacalcidol as a vitamin $\mathrm{D}$ substitute, aiming at an intact parathyroid hormone (iPTH) level of high normal to twofold the upper limit of normal $(50-100 \mathrm{ng} / \mathrm{L})$. Alphacalcidol was given daily in the beginning and switched to pulse therapy (three times per week) if the iPTH level increased rapidly to $>400 \mathrm{ng} / \mathrm{L}$ and the ionized-calcium phosphate product (ion-Ca $\times \mathrm{Pi}$ ) was $>2.5 \mathrm{mmol}^{2} / \mathrm{L}^{2}[18$, 19]. All patients received a multivitamin formula planned for uremic patients. No patient received growth hormone therapy.

\section{Laboratory values and solute clearances}

Specimens for laboratory tests were drawn at every visit to our hospital and to local hospitals (every 1-2 weeks). Serum ferritin was targeted to be $>100 \mu \mathrm{g} / \mathrm{L}$ and saturated transferrin $>20 \%$.

A 24-h dialysate collection was performed with the patient's normal dialysis prescription. We aimed at a weekly urea $\mathrm{Kt} / \mathrm{V}>3.0$ and a $\mathrm{C}_{\mathrm{cr}}$ level $>65 \mathrm{~L} /$ week per $1.73 \mathrm{~m}^{2}$. The clearances were calculated with the PD Adequest 2.0 computer program (Baxter Healthcare). A normalized protein catabolic rate (nPCR), representing each patient's nutritional protein status, was obtained from the PD Adequest 2.0 program.

Intravascular volume status, hypertension, and heart measures

For the intravascular volume status estimation, we used the mean blood pressure of measurements taken at 2-h intervals (with an oscillometric device) during a 24-h period, weight, plasma N-terminal atrial natriuretic peptide (ANP-N), and echocardiography evaluation. All tests were performed within a 24-h period.

Hypertension was defined according to the Second Task Force reference values for diastolic and systolic daytime blood pressure. Hypertension was indicated if the mean diastolic or systolic blood pressure exceeded the 95th percentile for age and gender [20]. The patient was considered to have hypervolemia if there was hypertension (especially in anuric patients), the clinical status showed overload, and the ANP-N exceeded $3 \mathrm{nmol} / \mathrm{L}$, in accordance with our previous results [5].

The echocardiography examinations were performed by one cardiologist (J-M.H.). The echocardiographic data consisted of a left ventricular end-diastolic dimension (LVEDD), left ventricular end-systolic dimension (LVESD), interventricular septal dimension at end-diastole (SeptD), left ventricular posterior wall thickness at enddiastole (LVPWD), and ejection fraction (EF). The refer- ence values for the linear dimensions (LVEDD, LVESD, SeptD, LVPWD) were calculated according to Lester et al. [21] whose equations on their study population of infants and small children took race, age, gender, height, weight, and heart rate (HR) into account. We also determined LVM using M-mode echocardiography and the Devereux formula [22]. The LVM data were analyzed according to Foster et al. [12] using a novel method of expressing LVM related to body size that gives an LV mass-for-height $\mathrm{Z}$-score, thus taking smaller children better into account. The 95th percentile was chosen as the cutoff point for LVH. The Zscores of the LV mass-for-height and heart dimensions were used for the correlation analyses. The LVM was also related to body height ${ }^{2.7}$, according to Simone et al. [23], to obtain a linear relationship and allow comparisons to be made and is here referred to as the left ventricular mass index (LVMI). LVH was considered if the LVMI exceeded the 95th percentile of the age group and gender [23].

\section{Growth}

Birth length $(n=18)$ and other height values are given as mean height standard deviation scores (ht SDS). Growth was reported 6 and 3 months before PD onset, if possible at baseline, and every 3 months thereafter. Growth is considered to be favorable, if the growth velocity is normal for age (ht SDS change $\geq 0$ during the study period). Bone age (BA) X-rays were taken at baseline and every 6 months thereafter. These were evaluated by one radiologist (E.M.) according to the Greulich-Pyle method which relates them to bone maturation in healthy Finnish children [24]. The BA data were lacking in seven patients at baseline and in six patients after 6 months. The parental target height (midparental height) was calculated using parental height measures according to Sorva et al. [25]. In evaluating growth, the patients' decimal ages were corrected according to the expected date of delivery.

\section{Statistical analyses}

The statistical analyses were performed using SPSS ver. 13.0 for Windows (SPSS, Chicago, IL). The values are expressed as the mean $\pm 1 \mathrm{SD}$ (standard deviation) unless otherwise stated. The growth, laboratory values, and weekly urea $\mathrm{Kt} / \mathrm{V}$ and $\mathrm{C}_{\mathrm{cr}}$ were analyzed with the analysis of variance (ANOVA) and Student's $t$ test, and comparisons with parent-specific height were performed using the Wilcoxon signed ranks test. The Friedman test with the Dunn test was used for comparing heart measures, clearances, and other laboratory values over time. Pearson's correlation coefficient was used for simple correlations, such as correlating intravascular volume status indicators at each time point, and Spearman's correlation was used for 
nonnormally distributed data. Statistical significance was defined as $P<0.05$.

This study was approved by the Ethics Committee for Pediatrics, Adolescent Medicine and Psychiatry at the University of Helsinki. Written informed consent was obtained from the parents of the patients after explaining the aim and the implementation of the study.

\section{Results}

Dialysis

The mean age at PD initiation was $0.59 \pm 0.33$ years, and mean duration of PD $1.13 \pm 0.57$ years (Table 1 ). The total time these patients were on PD was thus 284 months, including 174 months $(61 \%)$ on CCPD and 106 months $(38 \%)$ on TPD. Two patients needed HD (total time 3 months, 1\%) between PD periods. The mean waiting time for a kidney transplant from a deceased donor after the patient was put on the waiting list was $5.5 \pm 4.4$ months, resulting in a mean follow-up period of 13.6 months for growth evaluation on PD. The mean age at the end of the follow-up was $1.71 \pm 0.68$ years.

These children spent 65 days per patient-year in hospital after the initiation of dialysis. These 65 days were broken up into PD introduction, training of the family, and PD controls (46\%), complications of PD (28\%), other infections, operations, and investigations (18\%), and social causes (8\%).

One patient (5\%) died during PD of pneumonia after a complication from the anesthesia; other complications are presented in Table 1.

Nutrition and calcium-phosphate balance

The energy supply according to the 2-day food records was $84 \pm 22 \mathrm{kcal} / \mathrm{kg}$ per day, corresponding to $100 \pm 26 \%$ of the recommended dietary allowance (RDA). The RDA of energy was chosen according to the highest value of each age group [26, 27]. The protein intake was $2.3 \pm 0.6 \mathrm{~g} / \mathrm{kg}$ per day, corresponding to $181 \pm 50 \%$ of the safe level of supply (minimum) for each age group (safe levels 1.09$1.86 \mathrm{~g} / \mathrm{kg}$ per day) [28]. The vitamin supply was in the range of the RDA.

The mean alphacalcidol dose at 6 months was $0.34 \pm$ $0.35 \mu \mathrm{g} / \mathrm{kg}$ per week, and the mean calcium dose was $37 \pm$ $30 \mathrm{mg} / \mathrm{kg}$ per day. At the beginning of treatment, alphacalcidol was given daily to 20 patients, with one patient receiving pulse therapy. After 3 months, 12 patients received daily dosages, seven received pulse therapy, and two had pauses in medication due to low iPTH values. After 6, 9, and 12 months these numbers were 13 daily $/ 6$ pulse $/ 2$ pause, 11 daily $/ 4$ pulse/ 0 pause, and 4 daily $/ 5$ pulse $/ 0$ pause, respectively.
The ion- $\mathrm{Ca} \times \mathrm{Pi}$ level exceeded $2.5 \mathrm{mmol}^{2} / \mathrm{L}^{2}$ in $48 \%$ of the patients at baseline and in 43,28 , and $33 \%$ of the patients after 3, 6, and 9 months on PD, respectively. The iPTH values rose with time, mostly caused by the uremia that developed in patients with the congenital nephrotic syndrome of the Finnish type (NPHS1) after nephrectomy prior to dialysis, and 70\% had a value $<300 \mathrm{ng} / \mathrm{L}$ at 12 months $(30 \%<100 \mathrm{ng} / \mathrm{L})$. Alkaline phosphatase level was normal in our patients.

Metabolic control and solute clearances

The laboratory values during the first 9 months are given in Table 2. Since the patients lost sodium in their dialysate, with a mean loss of $30 \mathrm{mmol}$ per day, they needed sodium chloride supplementation $(n=19)$ to maintain their plasma sodium concentration in the low-normal range $(>135 \mathrm{mmol} / \mathrm{L})$. If the patient was hypertensive or hypervolemic, the sodium concentrate was withdrawn from the medication.

We performed a total of ninety $24-\mathrm{h}$ dialysate and urine (if not anuric) collections and clearance studies in our patients. The mean weekly urea $\mathrm{Kt} / \mathrm{V}$ and $\mathrm{C}_{\mathrm{cr}}$ were $3.38 \pm 0.66$ and $49 \pm$ $20 \mathrm{~L} /$ week per $1.73 \mathrm{~m}^{2}$, respectively (Table 2). The urea $\mathrm{Kt} /$ $\mathrm{V}$ of patients with residual renal function (RRF) $(3.52 \pm 0.85)$ was not significantly higher than that of anuric children (3.32 \pm 0.59$)$. The $\mathrm{C}_{\mathrm{cr}}$ levels were significantly better in RRF patients than in anuric patients: $66 \pm 27$ vs. $44 \pm 13 \mathrm{~L} /$ week per $1.73 \mathrm{~m}^{2}$, respectively $(P<0.001)$. However, the number of patients was too small for definitive conclusions to be drawn. Although plasma creatinine increased with time, especially in nephrectomized patients, the $C_{c r}$ levels remained stable (Table 2).

Intravascular volume status, hypertension, and heart measures

Hypertension was detected in eight patients $(40 \%)$ at initiation of PD and in six (29\%) at 3 months, seven (37\%) at 6 months, four (44\%) at 9 months, and four (57\%) at 12 months on PD. All patients with diagnosed hypertension were anuric. Nine patients $(43 \%)$ had longer hypertensive periods that lasted at least 3 months (Fig. 1).

Seven patients $(33 \%)$ received antihypertensive medication for at least 2 weeks during PD (Fig. 1). All but the patient with fibromuscular dysplasia needed only one antihypertensive drug to control blood pressure. We usually used calcium-channel blockers (felodipine or nifedipine), but the beta blocker metoprolol was also administered.

The mean plasma ANP-N values and blood pressures are given in Table 3. After 3 months on PD, when the patients were stable, high plasma ANP-N levels $(n=19)$ correlated well with both systolic and diastolic hypertension $(r=0.59$, $P=0.007$ and $r=0.57, P=0.011$ ), respectively. Good correlations were also seen at baseline and after 6 months on PD. 
Table 2 Laboratory values for the 21 patients $<2$ years of age on PD

\begin{tabular}{|c|c|c|c|c|c|}
\hline \multirow[t]{2}{*}{ Laboratory parameters } & \multicolumn{4}{|l|}{ Time on PD } & \multirow[t]{2}{*}{ Reference values } \\
\hline & Baseline $(n=21)$ & 3 months $(n=21)$ & 6 months $(n=18)$ & 9 months $(n=9)$ & \\
\hline BUN (mmol/L) & $33.5 \pm 10.2$ & $37.7 \pm 7.7$ & $35.2 \pm 7.2$ & $39.9 \pm 5.5$ & $4-14$ \\
\hline Creatinine $(\mu \mathrm{mol} / \mathrm{L})$ & $344 \pm 88$ & $428 \pm 111$ & $473 \pm 138$ & $516 \pm 147$ & $0-60$ \\
\hline Hemoglobin (g/L) & $103 \pm 11$ & $120 \pm 15$ & $112 \pm 14$ & $124 \pm 22$ & $111-142$ \\
\hline Bicarbonate $(\mathrm{mmol} / \mathrm{L})$ & $25 \pm 3$ & $25 \pm 3$ & $27 \pm 4$ & $26 \pm 3$ & $22-26$ \\
\hline Ionized calcium (mmol/L) & $1.28 \pm 0.08$ & $1.29 \pm 0.07$ & $1.26 \pm 0.07$ & $1.28 \pm 0.06$ & $1.17-1.35$ \\
\hline Phosphate (mmol/L) & $1.92 \pm 0.61$ & $1.84 \pm 0.44$ & $1.66 \pm 0.37$ & $1.97 \pm 0.31$ & $1.3-2.2$ \\
\hline Alkaline phosphatase (U/L) & $439 \pm 189$ & $870 \pm 342$ & $852 \pm 487$ & $745 \pm 420$ & $250-850$ \\
\hline Intact PTH median (range) (ng/L) & $58(8-106)$ & $145(7-1431)$ & $218(24-863)$ & $229(24-705)$ & $8-73$ \\
\hline Prealbumin $(\mathrm{mg} / \mathrm{L})$ & $319 \pm 125$ & $319 \pm 58$ & $341 \pm 67$ & $320 \pm 48$ & $95-280$ \\
\hline Triglycerides (mmol/L) & $3.47 \pm 1.97$ & $2.99 \pm 1.34$ & $2.79 \pm 1.5$ & $2.6 \pm 0.8$ & $0.34-1.24$ \\
\hline Total cholesterol (mmol/L) & $4.9 \pm 1.8$ & $5.2 \pm 1.7$ & $5.5 \pm 1.5$ & $5.1 \pm 0.8$ & $2-5.6$ \\
\hline HDL-cholesterol (mmol/L) & $1.05 \pm 0.44$ & $1.28 \pm 0.26$ & $1.27 \pm 0.29$ & $1.36 \pm 0.21$ & $0.91-2.12$ \\
\hline Creatinine clearance $\left(\mathrm{L} /\right.$ week $\left./ 1.73 \mathrm{~m}^{2}\right)$ & - & $48.8 \pm 19.1$ & $49.3 \pm 18.1$ & $48.8 \pm 29.7$ & \\
\hline Weekly urea Kt/V & - & $3.34 \pm 0.79$ & $3.46 \pm 0.56$ & $3.49 \pm 0.78$ & \\
\hline Protein catabolic rate (g/kg per day) & - & $3.52 \pm 0.57$ & $3.22 \pm 0.52$ & $3.22 \pm 0.40$ & \\
\hline
\end{tabular}

All values are the mean $\pm 1 \mathrm{SD}$ (standard deviation)

BUN, Blood urea nitrogen; PTH, parathyroid hormone; HDL, high-density lipoprotein

The heart dimension and LV mass-for-height Z-scores are presented in Table 3. LVH (Z-scores, $n=19)$ correlated well with both systolic and diastolic hypertension $(r=0.67$, $P=0.002$ and $r=0.54, P=0.017$, respectively), but not with the plasma ANP-N of patients on PD for 3 months. LVEDD and systolic hypertension $(n=15)$ also showed good

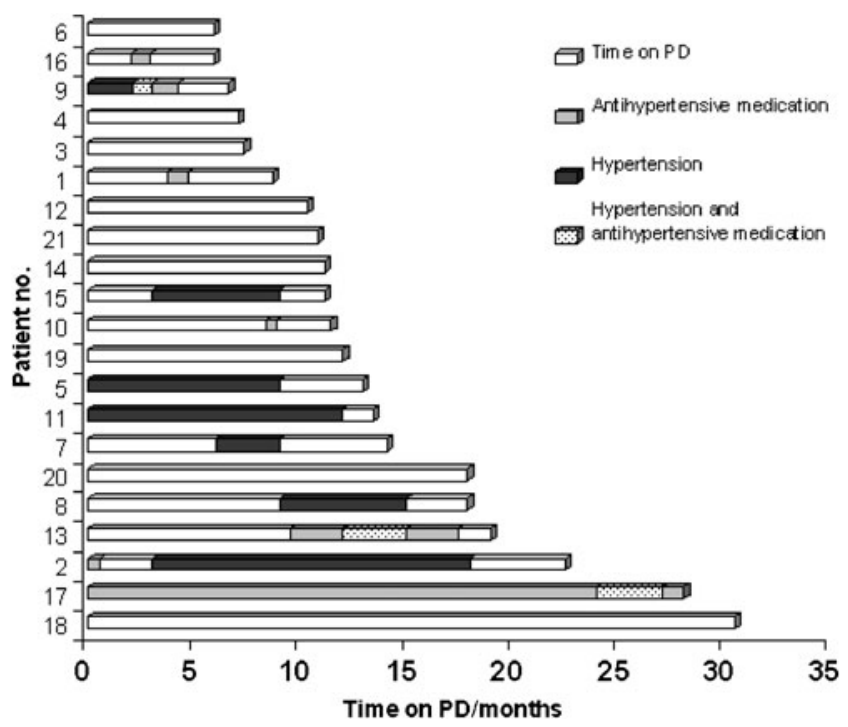

Fig. 1 Long-term hypertension (duration at least 3 months) and antihypertensive medication in 21 infants during peritoneal dialysis $(P D)$ correlation at 3 months $(r=0.62, P=0.013)$. All of these correlations and the same order of magnitude were also seen at initiation of PD and at 6 months. The LVEDD decreased significantly between baseline and 3 months $(P=$ $0.002)$ and between baseline and 6 months $(P=0.024)$. The mean LVMI of patients was $105 \pm 30 \mathrm{~g} / \mathrm{m}^{2.7}$ (LVH in $86 \%$ of the patients) at baseline, $84 \pm 32 \mathrm{~g} / \mathrm{m}^{2.7}$ ( $\mathrm{LVH}$ in $63 \%$ ) after 3 months on PD, and $78 \pm 24 \mathrm{~g} / \mathrm{m}^{2.7}$ (LVH in $35 \%$ ) after 6 months on PD. Based on these assessment methods (LV mass-for-height and LVMI), the proportion of children with $\mathrm{LVH}$ decreased during $\mathrm{PD}$, and this improvement was statistically significant for both LV mass-for-height $Z$-scores ( $P=0.016$, PD start vs. 3 months; $P=0.035$, PD start vs. 6 months) and LVMI ( $P=0.027,3$ vs. 6 months on PD; $P=$ 0.006 , PD start vs. 6 months). The mean $\mathrm{EF}$ in our patients was normal: $58.9 \pm 8.4 \%$ at baseline, $60.4 \pm 9.7 \%$ after 3 months on PD, and $62.1 \pm 8.2 \%$ after 6 months on PD.

\section{Growth}

In this cohort of infants, there was a decrease in the mean height standard deviation score (SDS) from birth to their initiation to dialysis. At birth, the mean ht SDS $(n=18)$ was $-0.69 \pm 1.54$ and at PD initiation, it was $-1.29 \pm 1.20$. After dialysis initiation and the regular routine of standardized care, we observed a significant increase in mean ht SDS. At 6 months on PD, the mean ht SDS $(n=18)$ was $-1.02 \pm 0.98$. Fifteen patients were dialyzed at least 9 months, and their mean ht 
Table 3 Linear heart dimensions and LV mass-for-height Z-scores and the percentage of patients exceeding the 95 th percentile in 21 patients $<2$ years of age at onset of PD

\begin{tabular}{|c|c|c|c|c|c|c|}
\hline \multirow[t]{3}{*}{ Measures } & \multicolumn{6}{|c|}{ PD duration } \\
\hline & \multicolumn{2}{|c|}{ Baseline $(n=16)$} & \multicolumn{2}{|c|}{3 months $(n=15)$} & \multicolumn{2}{|c|}{6 months $(n=17)$} \\
\hline & Z-score & $\begin{array}{l}\text { Proportion }>95 \text { th } \\
\text { percentile }\end{array}$ & Z-score & $\begin{array}{l}\text { Proportion }>95 \text { th } \\
\text { percentile }\end{array}$ & Z-score & $\begin{array}{l}\text { Proportion }>95 \text { th } \\
\text { percentile }\end{array}$ \\
\hline \multicolumn{7}{|l|}{ Heart dimensions } \\
\hline LVEDD [21] & $0.28 \pm 1.80$ & $31 \%$ & $-1.55 \pm 1.55$ & $0 \%$ & $-0.83 \pm 1.43$ & $6 \%$ \\
\hline LVESD [21] & $0.21 \pm 1.75$ & $19 \%$ & $-1.74 \pm 1.77$ & $0 \%$ & $-1.46 \pm 1.97$ & $12 \%$ \\
\hline SeptD [21] & $2.91 \pm 1.80$ & $87 \%$ & $3.17 \pm 1.72$ & $80 \%$ & $3.18 \pm 1.17$ & $94 \%$ \\
\hline LVPWD [21] & $2.34 \pm 1.54$ & $56 \%$ & $1.79 \pm 2.11$ & $60 \%$ & $2.21 \pm 1.45$ & $59 \%$ \\
\hline LV mass-for-height $[12]^{\mathrm{a}}$ & $0.96 \pm 1.65$ & $33 \%$ & $-0.09 \pm 1.94$ & $16 \%$ & $-0.07 \pm 1.41$ & $18 \%$ \\
\hline \multicolumn{7}{|l|}{ Volume indicators } \\
\hline Plasma ANP-N $(\mathrm{nmol} / \mathrm{L})^{\mathrm{b}}$ & $8.9 \pm 8.7$ & & $2.7 \pm 1.2$ & & $3.3 \pm 1.9$ & \\
\hline Systolic BP $(\mathrm{mmHg})^{\mathrm{c}}$ & $105 \pm 18$ & $40 \%$ & $101 \pm 20$ & $29 \%$ & $104 \pm 18$ & $37 \%$ \\
\hline Diastolic BP $(\mathrm{mmHg})^{\mathrm{c}}$ & $56 \pm 10$ & $0 \%$ & $56 \pm 14$ & $14 \%$ & $55 \pm 12$ & $11 \%$ \\
\hline
\end{tabular}

All values are given as the mean $\pm 1 \mathrm{SD}$

LVEDD, Left ventricular end-diastolic dimension; LVESD, left ventricular end-systolic dimension; SeptD, interventricular septal dimension at end-diastole; LVPWD, left ventricular posterior wall thickness at end-diastole; ANP-N, N-terminal atrial natriuretic peptide; BP, blood pressure

${ }^{a} n=21$ at baseline, $n=18$ at 3 months, and $n=17$ at 6 months

${ }^{\mathrm{b}} n=18$ at baseline, $n=19$ at 3 months, and $n=17$ at 6 months

${ }^{\mathrm{c}} n=20$ at baseline, $n=21$ at 3 months, and $n=19$ at 6 months

SDS was $-1.59 \pm 1.19$ at initiation and $-1.19 \pm 1.25$ after 9 months. These differences were not statistically significant. However, when the whole dialysis period in all patients was considered, the mean ht SDS scores were $-1.29 \pm 1.20$ and $-0.86 \pm 0.99(P=0.036)$ at onset and at the end of PD, respectively. Individual growth curves are given in Fig. 2. Catch-up growth was documented in 12 patients (57\%) during PD.

At baseline, the mean BA was $0.62 \pm 0.35$ years compared with the mean decimal age of $0.67 \pm 0.25$ years; the correlation was favorable $(r=0.74, P=0.003)$. After 6 months, the mean BA was $1.19 \pm 0.34$ years, with a mean decimal age of $1.20 \pm 0.27$ years, and the correlation was moderate $(r=0.53, P=0.043)$.

Although these children grew well during dialysis, their height lagged significantly compared with their parental target ht SDS during dialysis and at the end of PD at a mean age of 1.71 years $(P<0.01$ at initiation of $\mathrm{PD}$, 6 months on PD, and at the end) (Fig. 3).

\section{Discussion}

The results of our prospective study show that it is possible to maintain favorable metabolic control and ensure normal growth in infants during PD. However, the children enrolled in our study were still significantly smaller than their parental target height predicted at the end of infancy. In addition, problems remained in treating hyperparathyroidism and hypertension, while hypervolemia stressed the heart in many patients.

Nutrition and metabolic balance were favorable among our patients, but protein intake was much higher than recommended in the newest Kidney Disease Outcomes Quality Initiative (KDOQI) guidelines. Our patients received $2.3 \pm 0.6 \mathrm{~g} / \mathrm{kg}$ protein per day compared with recent recommendations of $1.5-1.8 \mathrm{~g} / \mathrm{kg}$ per day for children $<1$ year of age and $1.3 \mathrm{~g} / \mathrm{kg}$ per day for children between 1 and 3 years [29]. The more protein in the diet, the more phosphorus the patient receives, which in turn increases the requirement for phosphate binders, which currently are mostly calcium-based. Thus, $>40 \%$ of our patients had an ion-Ca $\times \mathrm{Pi}$ that was higher than recommended. Most of our patients were in a state of protein malnutrition at the initiation of PD due to protein losses before nephrectomy in the NPHS1 patients. Although these patients needed protein substitution at $\mathrm{PD}$ initiation, their protein intake should probably have been reduced after a few months on PD to avoid excess calcium. 


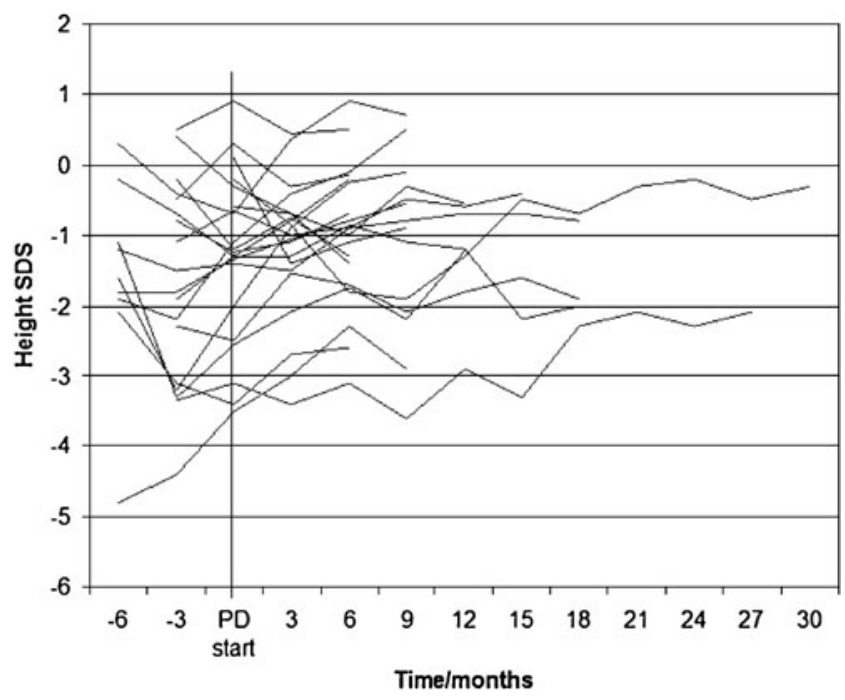

Fig. 2 Height standard deviation score (SDS) in 21 PD patients $<2$ years of age at 6 and 3 months prior to PD initiation, at PD initiation, and up to the end of PD

We reached the target iPTH level in only $30 \%$ of our children, but $70 \%$ had a concentration $<300 \mathrm{ng} / \mathrm{L}$, and their calcium, phosphate, and alkaline phosphatase concentrations as well as growth were quite acceptable.

The weekly Kt/V levels for urea, which describe the clearance of small molecules, were favorable in our patients throughout the dialysis period. Clearance of the midsized molecules can be studied by two different methods-the conventional method, weekly $\mathrm{C}_{\mathrm{cr}}$, and weekly creatinine $\mathrm{Kt} / \mathrm{V}$. Among our patients, the $\mathrm{C}_{\mathrm{cr}}$ levels were far lower than our target level, especially in nephrectomized children, but these infants still grew well during the dialysis period. In our earlier studies, the $24-\mathrm{h}$ clearances were $13-15 \%$ higher than with the patients' normal dialysis program (used here) due to an additional long dwell as part of the peritoneal equilibration test [6,7]. Moreover, it is important to note that $\mathrm{C}_{\mathrm{cr}}$ is related to $\mathrm{BSA}$, which is relatively large in infants compared with that of older children or adults and which may explain some of these lower $\mathrm{C}_{\mathrm{cr}}$ values. The method based on weekly creatinine $\mathrm{Kt} / \mathrm{V}$ was reported by Ishikura et al. [30] to correlate the clearance of creatinine with total body water in contrast to BSA. In adult patients (male; $170 \mathrm{~cm}, 65 \mathrm{~kg}$ ), a $\mathrm{C}_{\mathrm{cr}}$ level of $60 \mathrm{~L} /$ week per $1.73 \mathrm{~m}^{2}$ corresponds to a weekly creatinine $\mathrm{Kt} / \mathrm{V}$ of 1.52 [30]. In our patients, the mean $\mathrm{C}_{\mathrm{cr}}$ was $49 \pm 20 \mathrm{~L} /$ week per $1.73 \mathrm{~m}^{2}$ and the mean creatinine $\mathrm{Kt} / \mathrm{V}$ was $2.19 \pm 0.91$. A weekly creatinine $\mathrm{Kt} / \mathrm{V}$ value of 1.52 is equivalent to a $\mathrm{C}_{\mathrm{cr}}$ level of $35 \mathrm{~L} /$ week per $1.73 \mathrm{~m}^{2}$. The mean weekly $\mathrm{C}_{\mathrm{cr}}$ level was $1.92 \pm 0.58$ in anuric patients and $3.01 \pm 1.22$ in children with RRF. Our data suggest that $\mathrm{C}_{\mathrm{cr}}$ values as low as $40 \mathrm{~L} /$ week per $1.73 \mathrm{~m}^{2}$ in infants are acceptable for good growth if the nutrition is optimal and the clinical status and metabolic control of the patients are favorable. Although randomized prospective trials would be optimal to definitely answer this question, it is difficult to obtain enough children, and such studies may be difficult to perform within an acceptable ethical context.

A total of $57 \%$ of our patients had a systolic blood pressure over the 95th percentile at some point during dialysis; in our previous study, this percentage was $73 \%$ in patients $<5$ years of age [5]. Thus, there was less hypertension among the patients of the present study, but high blood pressure still remained a problem during PD. Only $10 \%$ of our patients had antihypertensive medication at baseline compared with $55 \%$ of the patients at baseline in the above-mentioned earlier study [5]. At baseline we often observed hypertension being caused by hypervolemia and were reluctant to begin antihypertensive medication. Instead, we increased ultrafiltration to achieve euvolemia. The sodium supplementation used in most patients could scarcely be considered a cause of hypertension since plasma sodium values as low as $135 \mathrm{mmol} /$ $\mathrm{L}$ were accepted as adequate. In nephrectomized infants, the best predictors of intravascular volume status in our study were blood pressure and echocardiography. If the patient has hypervolemia and is hypertensive, ultrafiltration should be increased. However, in anuric patients more care is needed in reacting to high blood pressure values. We also used bioimpedance analysis (BIA) in our study, but the measurements were technically demanding, and the results were of no value in estimating intravascular volume status, mainly because we lacked the normal values for this age group. We still miss good tools to estimate dry weight and intravascular volume status in infants. Keeping blood pressure near the lower normal limit increases the risk for hypovolemia during vomiting, perspiration, fever, and infections. Severe hypovo-

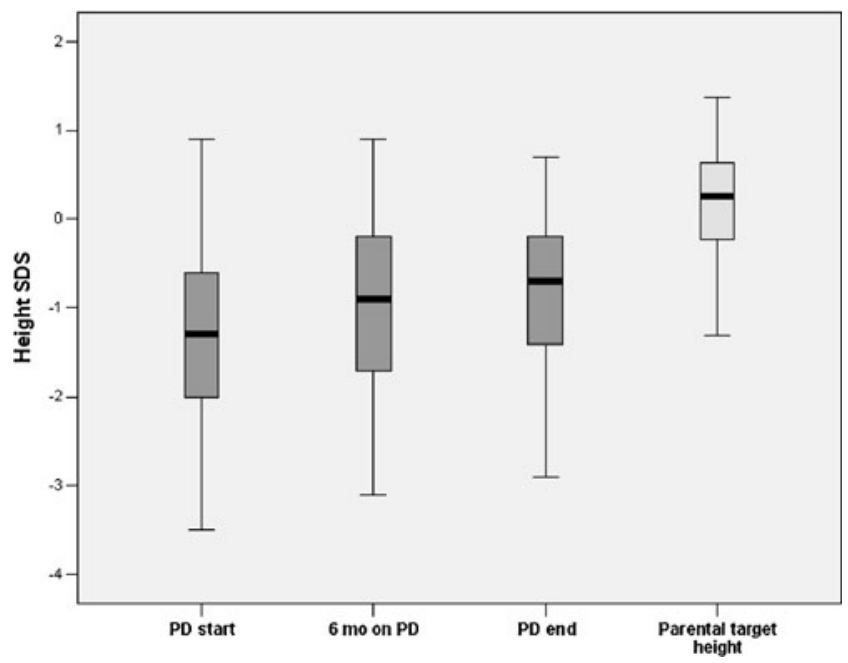

Fig. 3 Height SDS levels $(n=21)$ in infants at PD start, after 6 months, and at the end of PD (darker bars) compared with their target height SDS (lighter bar). Median, quartiles, and extreme values are presented 
lemia may even cause brain damage [10,31]. It is therefore probably safer to allow mild hypervolemia in infants.

A total of $86 \%$ of our patients had an LVMI exceeding the 95 th percentile at baseline, compared with $60 \%$ of the patients $<5$ years of age in our previous study [5]. On the other hand, using a novel method developed by Foster et al., which is especially useful for young patients [12], LVH was found in only $33 \%$ of our patients at baseline. During PD, the proportion of patients with LVH and LVEDD Zscores over the 95th percentile decreased, indicating successful management of intravascular volume status and hypertension. Plasma ANP-N reflects current intravascular volume status, while LVM changes only slowly. This is likely to be the reason why the ANP-N did not correlate with LVH.

Infants were formerly observed to grow poorly during PD. More recent reports, however, demonstrate good growth in this age group [6, 7, 32, 33]. None of these earlier reports compared gained height with midparental height. Luo et al. [34] showed that length at birth had a negative influence on catch-up growth during infancy, but not thereafter, while parent-specific height had a positive effect on catch-up growth from the onset of childhood. Our children had a normal mean height at birth $(-0.69$ SDS), but although they grew normally for age during PD, they did not reach their midparental height at about 18-24 months of age because they lost relative height prior to optimal renal replacement therapy. Their final height can only be documented when growth has ceased in young adulthood, and follow-up after renal transplantation will show if these children finally attain their midparental height, although at a later age than could be expected.

In conclusion, we have largely been able to optimize growth and metabolic control during dialysis, mainly due to optimal food intake in combination with sufficient dialysis dose, but the time before PD initiation is of the outmost importance, as shown by the decrease in growth prior to PD. Even with normal growth during PD, often with catchup, midparental height is not attained at the end of infancy. Thus, we suggest that early diagnoses, sufficient diet, and metabolic control prior to dialysis are crucial for the longterm outcome of these children and should improve growth closer to their parental target height. Several instruments are needed for intravascular volume status control during PD. Our patient population was small but very homogenous, and the results are congruent with previous retrospective reports.

Open Access This article is distributed under the terms of the Creative Commons Attribution Noncommercial License which permits any noncommercial use, distribution, and reproduction in any medium, provided the original author(s) and source are credited.

\section{References}

1. Bunchman TE (1996) The ethics of infant dialysis. Perit Dial Int 16(Suppl 1):S505-S508

2. Geary DF (1998) Attitudes of pediatric nephrologists to management of end-stage renal disease in infants. J Pediatr 133:154-156

3. Hijazi R, Abitbol CL, Chandar J, Seeherunvong W, Freundlich M, Zilleruelo G (2009) Twenty-five years of infant dialysis: A single center experience. J Pediatr 155:111-117

4. Shooter M, Watson A (2000) The ethics of withholding and withdrawing dialysis therapy in infants. Pediatr Nephrol 14:347-351

5. Holtta T, Happonen JM, Ronnholm K, Fyhrquist F, Holmberg C (2001) Hypertension, cardiac state, and the role of volume overload during peritoneal dialysis. Pediatr Nephrol 16:324-331

6. Holtta T, Ronnholm K, Jalanko H, Holmberg C (2000) Clinical outcome of pediatric patients on peritoneal dialysis under adequacy control. Pediatr Nephrol 14:889-897

7. Laakkonen H, Holtta T, Lonnqvist T, Holmberg C, Ronnholm K (2008) Peritoneal dialysis in children under two years of age. Nephrol Dial Transplant 23:1747-1753

8. Qvist E, Pihko H, Fagerudd P, Valanne L, Lamminranta S, Karikoski J, Sainio K, Ronnholm K, Jalanko H, Holmberg C (2002) Neurodevelopmental outcome in high-risk patients after renal transplantation in early childhood. Pediatr Transplant 6:53-62

9. Holtta TM, Ronnholm KA, Jalanko H, Ala-Houhala M, Antikainen M, Holmberg C (1997) Peritoneal dialysis in children under 5 years of age. Perit Dial Int 17:573-580

10. Lapeyraque AL, Haddad E, Andre JL, Bremond-Gignac D, Taylor CM, Rianthavorn P, Salusky IB, Loirat C (2003) Sudden blindness caused by anterior ischemic optic neuropathy in 5 children on continuous peritoneal dialysis. Am J Kidney Dis 42:E3-E9

11. Foppa M, Duncan BB, Rohde LE (2005) Echocardiography-based left ventricular mass estimation. How should we define hypertrophy? Cardiovasc Ultrasound 3:17

12. Foster BJ, Mackie AS, Mitsnefes M, Ali H, Mamber S, Colan SD (2008) A novel method of expressing left ventricular mass relative to body size in children. Circulation 117:2769-2775

13. National Kidney Foundation (1997) NKF-DOQI clinical practice guidelines for peritoneal dialysis adequacy. Am J Kidney Dis 30: S67-S136

14. Durand PY, Chanliau J, Gamberoni J, Hestin D, Kessler M (1992) Routine measurement of hydrostatic intraperitoneal pressure. Adv Perit Dial 8:108-112

15. Fischbach M, Desprez P, Donnars F, Geisert J (1994) Hydrostatic intraperitoneal pressure in children on peritoneal dialysis: practical implications. an 18-month clinical experience. Adv Perit Dial 10:294-296

16. Fischbach M, Terzic J, Laugel V, Escande B, Dangelser C, Helmstetter A (2003) Measurement of hydrostatic intraperitoneal pressure: a useful tool for the improvement of dialysis dose prescription. Pediatr Nephrol 18:976-980

17. Ronnholm KA, Holmberg C (2006) Peritoneal dialysis in infants. Pediatr Nephrol 21:751-756

18. Tertti R, Harmoinen A, Leskinen Y, Metsarinne KP, Saha H (2007) Comparison of calcium phosphate product values using measurement of plasma total calcium and serum ionized calcium. Hemodial Int 11:411-416

19. Klaus G, Watson A, Edefonti A, Fischbach M, Ronnholm K, Schaefer F, Simkova E, Stefanidis CJ, Strazdins V, Vande Walle J, Schroder C, Zurowska A, Ekim M, European Pediatric Dialysis Working Group (EPDWG) (2006) Prevention and treatment of renal osteodystrophy in children on chronic renal failure: European guidelines. Pediatr Nephrol 21:151-159

20. National High Blood Pressure Education Program Working Group on Hypertension Control in Children and Adolescents (1996) 
Update on the 1987 task force report on high blood pressure in children and adolescents: A working group report from the national high blood pressure education program. National high blood pressure education program working group on hypertension control in children and adolescents. Pediatrics 98: 649-658

21. Lester LA, Sodt PC, Hutcheon N, Arcilla RA (1987) M-mode echocardiography in normal children and adolescents: some new perspectives. Pediatr Cardiol 8:27-33

22. Devereux RB, Alonso DR, Lutas EM, Gottlieb GJ, Campo E, Sachs I, Reichek N (1986) Echocardiographic assessment of left ventricular hypertrophy: comparison to necropsy findings. Am J Cardiol 57:450-458

23. de Simone G, Daniels SR, Devereux RB, Meyer RA, Roman MJ, de Divitiis O, Alderman MH (1992) Left ventricular mass and body size in normotensive children and adults: assessment of allometric relations and impact of overweight. J Am Coll Cardiol 20:1251-1260

24. Marttinen E (1983) The growth of hand bones in relation to some body dimensions in normal children and certain forms of short stature. University of Helsinki, Helsinki

25. Sorva R, Tolppanen EM, Lankinen S, Perheentupa J (1989) Growth evaluation: parent and child specific height standards. Arch Dis Child 64:1483-1487

26. Food and Agriculture Organization of the WHO (2001) Human energy requirements. Report of a joint $\mathrm{FAO} / \mathrm{WHO} / \mathrm{UNU}$ expert consultation. FAO, Rome
27. Nordic Council of Ministers (2004) Nordic nutrition recommendations NNR 2004 - integrating nutrition and physical activity. Report No. 13. Nordic Council of Ministers, Copenhagen

28. World Health Organization (WHO) (1985) Energy and protein requirements. report of a joint $\mathrm{FAO} / \mathrm{WHO} / \mathrm{UNU}$ expert consultation. WHO Technical Report Series 724. WHO, Geneva

29. KDOQI Work Group (2009) KDOQI clinical practice guideline for nutrition in children with CKD: 2008 update. executive summary. Am J Kidney Dis 53(S11):104

30. Ishikura K, Hataya H, Ikeda M, Honda M (2003) Suitable dialytic indicators for pediatric peritoneal dialysis patients: the alternative to creatinine clearance. Perit Dial Int 23:270-275

31. Laakkonen H, Lonnqvist T, Uusimaa J, Qvist E, Valanne L, Nuutinen M, Ala-Houhala M, Majamaa K, Jalanko H, Holmberg C (2006) Muscular dystonia and athetosis in six patients with congenital nephrotic syndrome of the Finnish type (NPHS1). Pediatr Nephrol 21:182-189

32. Ledermann SE, Scanes ME, Fernando ON, Duffy PG, Madden SJ, Trompeter RS (2000) Long-term outcome of peritoneal dialysis in infants. J Pediatr 136:24-29

33. Kari JA, Gonzalez C, Ledermann SE, Shaw V, Rees L (2000) Outcome and growth of infants with severe chronic renal failure. Kidney Int 57:1681-1687

34. Luo ZC, Albertsson-Wikland K, Karlberg J (1998) Length and body mass index at birth and target height influences on patterns of postnatal growth in children born small for gestational age. Pediatrics 102:E72 